after which numbers rose rapidly-presumably as the southern air from the west was encountered. Such a clear and potentially valuable correspondence between air-masses and their spore, etc., load is largely to be expected when we think in terms of regions of origin, and perhaps is not necessarily much confused by mixing or loss by sedimentation, etc., even during long and tortuous travels.

(6) Analysis of the paths of the air-masses in which the other flights were made seems less significant, and in any case Mr. McLeod warned that in these instances the lack of upper-wind data made their earlier movements doubtful. However, it seems that the second sortie was in northerly winds coming from arctic Canada, and probably of just that originwhich may well explain the lack of uredospores and gymnospermous pollen and the general paucity of material caught. The third sortie, however, is interesting in its seeming support of the implication of the previous paragraph that the load of particles, etc., carried by an air-mass depends more on its origin, or at least its history, than on its trajectory or actual position at any time : for whereas the early stages of this flight were made in air-masses coming from the north, as was the case in the second flight, and the results were similarly so nearly negative that the slides constituted a kind of control, the last stage coming in towards Yellowknife was in air of north. westerly origin, which appeared to have a trajectory not unlike that of the air-mass in which the first flight of all was made, and actually showed a more comparable spore load.

(7) It appears that although the smaller spores of crop pathogens are alone apt to be at all numerous, pollen grains and other spores of a wide variety of types and especially of anemophilous species carry quite well in the atmosphere, and certainly some can occur at high altitudes ${ }^{7}$ and in remote regions not merely over land but also over the oceans. All too little is yet known of the extent to which they may remain viable; but it has been determined that a range of pollens of by no means hardy types can give a high percentage of germination and produce strong seedlings even after the greater part of a year of storage, and that low temperatures and light. intensities and atmospheric pressure (but medium humidities) can favour pollen longevity,10. In these and other circumstances, such as the almost perpetual windiness preventing particles from settling, it seems conceivable that the possibilities of long-range and hence 'absent-treatment' hybridization even among plants which do not practise the 'spring-flowering idea' may be greater in the Arctic than in some climatically more favourable regions where dense foliage, etc., impedes take-up and effective falling of 'pollen rain'-as well as where much of the atmospheric pollen is removed by precipitation-and may perhaps be one of the factors behind the tiresome 'plasticity' of many groups of arctic plants, including, particularly, the Gramineæ, Cyperacex, Juncaceæ, Salicace:e, Cruciferæ, Rosaceæ, and Compositæ.

In conclusion, it should be re-emphasized that these suggestions are largely tentative, being based. on too limited experience and too few data to allow sound generalization. It may even be objected that the small numbers of significant items observed on many of the slides are not beyond the possibilities of contamination; but the precautions taken, the advice of examining specialists, the working of controls, and the over-all picture now that it is possible to see it, all give confidence that even individual observations have value and probable validity. The above data are published with the approval of the Defense Research Board of Canada, which has generously supported the continuation of this work with an extra-mural grant in my name.

1 Nature, 160, 876 (1947).

Nature, 162, 379 (1948)

- Polunin, Nicholas, Pady, S. M., and Kelly, C. D., Arctic, 1,60 (1948). - Meier, Fred C. land Lindbergh, Charles A.l, Scient. Mon., 40, 5 (1935).

'Drakowska, J., Bull. Internat. de l'Acad. Polonaise... Série B, Seiences Naturelles (1), 1947 (Cracovie), pp. 25-33 (1948).

- In Polunin's "Botany of the Canadian Eastern Arctic. Part 2, Thillophyta and Bryoplyta". Py. $v+573$. (Ottawa : King's Printer, 1947.

Proctor, Bernard E., and Parker, Basil W., in "Aerobiology", ed. F. R. Moulton. Pp. $x+289$. (Washington, D.C., 1942.)

- Erdtman, G., Acta Horti Gotoburgensis, 12, 185 (1937).

Pfeiffer, N. E., Contr. Boyce Thompson Institute, 9, 199 (1938); 13,281 (1944)

${ }^{10}$ Pfeiffer, N. E., Contr. Boyce Thompson Institute, 8, 141 (1936); $10,429(1939)$.

\section{THE JOULE MUSEUM, SALFORD}

THE Joule Museum, which was opened on July 3 at Joule House, Salford, contains a permanent exhibition of apparatus and documents and is intended to be a comprehensive presentation, by original or replica, of J. P. Joule's major scientific work. The existence of this exhibition is due to the initiative of the British Society for the History of Science, which delegated the task of forming the Museum to Prof. L. Rosenfeld, University of Manchester ; in this, Mr. J. A. Newth was a ubiquitous lieutenant.

The nucleus of the Museum is a collection of original apparatus and documents which had been acquired by the Manchester College of Technology-through the agency of Prof. W. W. Haldane Geo-after Joule's death, when his house and property at Sale were disposed of. They have since been preserved at the College of Technology, where they could not be properly exhibited for lack of space. This collection has now been completed by replicas from original apparatus preserved elsewhere, and the whole has been displayed in a room of a house at Salford in which Joule lived for some years, and which is now owned by Salford Corporation. A grant of money from the University of Manchester and the provision of this room in Joule House, arranged by Mr. A. J. Rivett, director of education for Salford, made it possible to display the collection to the best advantage.

The replicas of apparatus have been constructed by Mr. R. Bradford in the workshop of the Physics Department of the University of Manchester. Apparatus was lent for this purpose by the Science Museum, South Kensington, London, through the agency of Mr. J. Chaldecott, and by the Department of Natural Philosophy, University of Glasgow, with the co-operation of Prof. P. I. Dee. The documents comprise a large laboratory book, some notebooks, manuscripts and letters, which come from a variety of sources.

The exhibits are arranged in sections which follow each other chronologically. The early experiments sprang out of a desire to improve Sturgeon's electromagnetic engine, and to arrive at a quantitative estimate of its "duty" or efficiency. There are shown a number of toy-like models of electrical motors and cores of electromagnets of various constructions which were used to study their "lifting-power". This section recalls Joule's friendship for William Sturgeon, 
whose encouragement may have determined the direction of these early experiments.

In the next period (1840-43) was performed a series of experiments concerned with the connexion between electricity and heat. A reconstruction of the simple apparatus which Joule used to measure the heat produced in a conductor by an electrical current is shown, together with a replica of the remarkable arrangement by which he confirmed his allegiance to the theory that heat is a mode of motion, and first established the equivalence between work and heat. A coil is mounted inside a cylindrical calorimeter $(25 \mathrm{~cm} . \times 10 \mathrm{~cm}$.) and can be rotated between the poles of a fixed electromagnet. Joule was able to show that heat is actually genorated in the coil by the induced current and that this heat is proportional to the mechanical work done in turning the apparatus. Direct voltaic currents were superimposed on those induced in the coil, and the measurements of the heat produced led to the conclusion that, in these experiments, mechanical work was converted into heat through the intermediary of electricity.

In 1844 Joule turned to a study of the heat changes accompanying the expansion and compression of gases; the original apparatus used in this series of experiments is exhibited in a complete state. Two large cylindrical copper vessels were connected through a needle valve ("the invention of Mir. Ash, of this town"). One of the cylinders was evacuated; the other could be filled to a pressure of 22 atmospheres by 300 strokes of a hand-pump. By immersing the whole arrangement in a calorimeter and opening the valve, Joule discovered that "no change of temperature occurs when air is allowed to expand in such a way as not to develop mechanical power". Unknown to him, this law had already been found in 1806 by Gay-Lussac; it played an essential part in the reasoning by which Robert Mayer deduced in his own way the mechanical equivalent of heat in 1842.

The next period (1845-49) was occupied with the famous friction experiments. Replicas are shown of the two paddle-wheel calorimeters, for the friction of water and mercury, and of that which contained two metal plates in close contact and which was used to produce heat by the friction between solids. All these systems were activated by falling weights. Unhappily, the thermometers which were used in Joule's experiments and preserved by the Manchester Literary and Philosophical Society were destroyed in an air-raid; there remain but a few relevant documents, including the invoice from the French firm which supplied some of them.

One of the most important events of Joule's life was his meeting with William Thomson (later Lord Kelvin) at the British Association meeting of 1847. This was the beginning of a long period of fruitful co-operation and mutual stimulus. For Thomson, it was the starting-point of the investigations which led him, shortly after Clausius, to the recognition of the two fundamental laws of thermodynamics.

In exploring the consequences of these laws, Thomson pointed out that a gas would be cooled by allowing it to expand into a region of lower pressure, and in 1852 Joule and Thomson started a long series of experiments which confirmed this deduction. There are exhibited the wooden containers for the porous plugs which were used to separate the regions at high and low pressure, and the few other surviving parts of the apparatus.
Joule's last experimental work, in 1878, was a new accurate determination, by the paddle-wheel friction method, of the mechanical equivalent of heat. It was undertaken at the request of the British Association Committee on Standards of Electrical Resistance, in order to clear up a discrepancy between the previous friction value and that derived from the heating effect of a current passing through a resistance which had been compared with the standard issued by the Committee. A replica of the calorimeter used by Joule for this experiment is exhibited, together with Joule's British Association standard resistance. The resulting value for the equivalent was almost identical with that obtained thirty years before by the same method.

The last section of the exhibition is devoted partly to some instruments which were probably permanent features of Joule's laboratory, and partly to a selection from a number of odd pieces of apparatus used in minor investigations of a varied character-especially in a careful study of the mechanism of steam condensation. Joule's precision instruments were made by John B. Dancer, an optician and scientific instrument maker of great reputation who carried on business in Cross Street, Manchester, from 1841, and was himself a distinguished amateur of science.

Documents and letters of special interest are displayed at appropriate places in the various sections, and also in separate show-cases. On the walls hang a portrait of William Sturgeon and two portraits of Joule himself. One of them is a photograph of the portrait by Collier owned by the Royal Society, and exhibited by permission of the Council of the Society. The other is a large oil-painting on loan from the Manchester Literary and Philosophical Society, which replaces the original portrait by Patten destroyed in the air-raid of 1940 .

While the scientific aspect of Joule's investigations can be reconstructed in a fairly complete way, it is a matter of regret that so few documents have been preserved which could throw light on his personality. Why did he devote himself to scientific pursuits when so much else might have been expected of a rich brewer's son? Who taught him the rudiments of his craft, and inspired his father to build him a laboratory? Whence came that almost arrogant courage which relied on the visual subdivision of a thermometer interval into twenty parts for the enunciation of a new law of Nature? What gave him such an ascetic devotion to a principle when his city was crying out for technical improvements and inventions?

It would be interesting to know more of his relations with people like Dalton and William Sturgeon, of his wife and family. There is some evidence that he was handicapped by a physical deformity that may have made him a recluse. It is certainly true that the last years of his life were given up to the infirmity of old age. But it is strange that so much. can have been forgotten about a man whose life-span overlapped that of our fathers.

The Joule Museum is open to the public, on application to the offices of the Child Guidance Clinic on the ground floor of Joule House, 49 The Crescent, Salford; parties or individual visitors who would like to be accompanied by a member of the staff of the Physics Department of the University of Manchester should make arrangements in advance with Prof. L. Rosenfeld at the Department. 